\title{
From Microwave Filter to Digital Filter and Back Again
}

\author{
Dalby, Arne Brejning
}

Published in:

19th European Microwave Conference

Link to article, DOI:

10.1109/EUMA.1989.334081

Publication date:

1989

Document Version

Publisher's PDF, also known as Version of record

Link back to DTU Orbit

Citation (APA):

Dalby, A. B. (1989). From Microwave Filter to Digital Filter and Back Again. In 19th European Microwave Conference (pp. 892-897). IEEE. https://doi.org/10.1109/EUMA.1989.334081

\section{General rights}

Copyright and moral rights for the publications made accessible in the public portal are retained by the authors and/or other copyright owners and it is a condition of accessing publications that users recognise and abide by the legal requirements associated with these rights.

- Users may download and print one copy of any publication from the public portal for the purpose of private study or research.

- You may not further distribute the material or use it for any profit-making activity or commercial gain

- You may freely distribute the URL identifying the publication in the public portal

If you believe that this document breaches copyright please contact us providing details, and we will remove access to the work immediately and investigate your claim 


\author{
Arne B. Dalby *
}

\title{
ABSTRACT.
}

A new very simple state variable flow graph representation for interdigital transmission line bandpass filters is presented, which has led to two important results: 1) a new type of digital filter with properties, that surpass the properties of most other (all pole) digital filtertypes. 2) The study of the new digital filtertype has led to design formulas for interdigital transmission line filters that are very simple compared to the hitherto known formulas. The accuracy is the same or better.

\section{INTHODUCTIOK.}

In [1] a transmission wave (or propagation mode) flow graph for coupled transmission line filters, based on a matrik equation description was introduced, a flow graph which also may be used for a digital filter. The flow graph may be used for e.g. interdigital SCTL (Short Circuited Terminating Line) or OCTL (Open Circuit Terminating Line) filters etc.: For the interdigital filters, coupling between nonadjacent lines is ignored, and homogeneous dielectric is supposed. However, the flow graph may also be used for microstrip interdigital filters if the analysis and synthesis methods described in [2] to [5] are employed in a somewhat modif ied form.

In this paper it is shown how the analysis and synthesis procedures for the so calied Digital Interdigital Filters (DIF) [1] lead to design formulas for interdigital transmission line filters. These formulas are very 5 imple compared to the formulas presented by Matthei in [6]. They are, however, just as accurate.

Design formulas for both OCTL- and SCTL-interdigital filters are presented.

The author has shown, that the DIF has properties, that on almost all accounts surpass the properties of most other digital filtertypes. Although the DIF in its raw form is a bandpass filter, simple changes in the flow graph make it into e.g. a bandstop filter. The DIF is not in itself the subject of this paper, but the work, which has led to design formulas for the different types of DIF's, also led to design formulas for interdigital filters. It should be mentioned that the new digital filter is a State Space Wave Digital Filter, a filter type which hitherto has been deemed impractical [7].

* Engineering Academy of Denmark, Akademivej, building 451, DK 2800 Lyngby, Denmark. 
The terminating impedances (impedance matrices) (4) for a coupled transmission line filter may be chosen to make the filter into e.g. a SCTL- or a OCTL-interdigital filter.

In [1] it is shown that, if the transmission 1 ines all have the same electrical length (homogeneous dielectric), then the same matrix equation describe the behavior of the filters, losses not taken into account. This matrix equation, is presented in (1) for a filter with output at the opposit end of the input. The reflexion coefficient matrices $\underline{e}_{1}$ and $\underline{e}_{2}(2),(3)$ are expressed in terms of the capacitance matrix cor the coup-led strips and the termination impedance matrices $\underline{Z}_{g}$ and $\underline{z}_{1}$ (4).

The vectors $\underline{v}_{g}$ and $\underline{v}_{2}$ represent the generator voltages (normally only one) and the voltages across the load impedances. Normally only one output voltage is of interest.

$$
\begin{aligned}
& 2 \cdot \underline{v}_{2}=\left(\underline{\underline{1}}+\underline{\underline{e}}_{2}\right) \cdot\left(\underline{\underline{1}}-\underline{\underline{e}}_{1} \cdot \underline{\underline{e}}^{2} \cdot z^{-x}\right)^{-1} \cdot z^{-1} \cdot\left(\underline{\underline{1}}-\underline{\underline{e}}_{1}\right) \cdot \underline{\mathrm{v}}_{\mathrm{g}}, z=\mathrm{e}^{5 \mathrm{~T}} \\
& \underline{\underline{e}}_{1}=\left(\underline{\underline{z}}_{1} \cdot v \cdot \underline{\underline{C}}+\underline{\underline{1}}\right)^{-1} \cdot\left(\underline{\underline{z}}_{1} \cdot v \cdot \underline{\underline{C}}-\underline{\underline{1}}\right) \\
& \underline{\underline{e}}_{z}=\left(\underline{\underline{z}}_{z} \cdot v \cdot \underline{\underline{c}}+1\right)^{-1} \cdot\left(\underline{\underline{z}}_{z} \cdot v \cdot \underline{\underline{\underline{c}}}-\underline{\underline{1}}\right)
\end{aligned}
$$

$$
\underline{\underline{z}}_{1}=\left\{\begin{array}{lllll}
z_{g 1} & z_{g 2} & & & \\
& & \cdot & \cdot & \\
& & & z_{g N}
\end{array}\right\}, \quad \underline{\underline{z}}_{2}=\left\{\begin{array}{llll}
z_{11} & z_{12} & & \\
& & \cdot & z_{1 N}
\end{array}\right]
$$
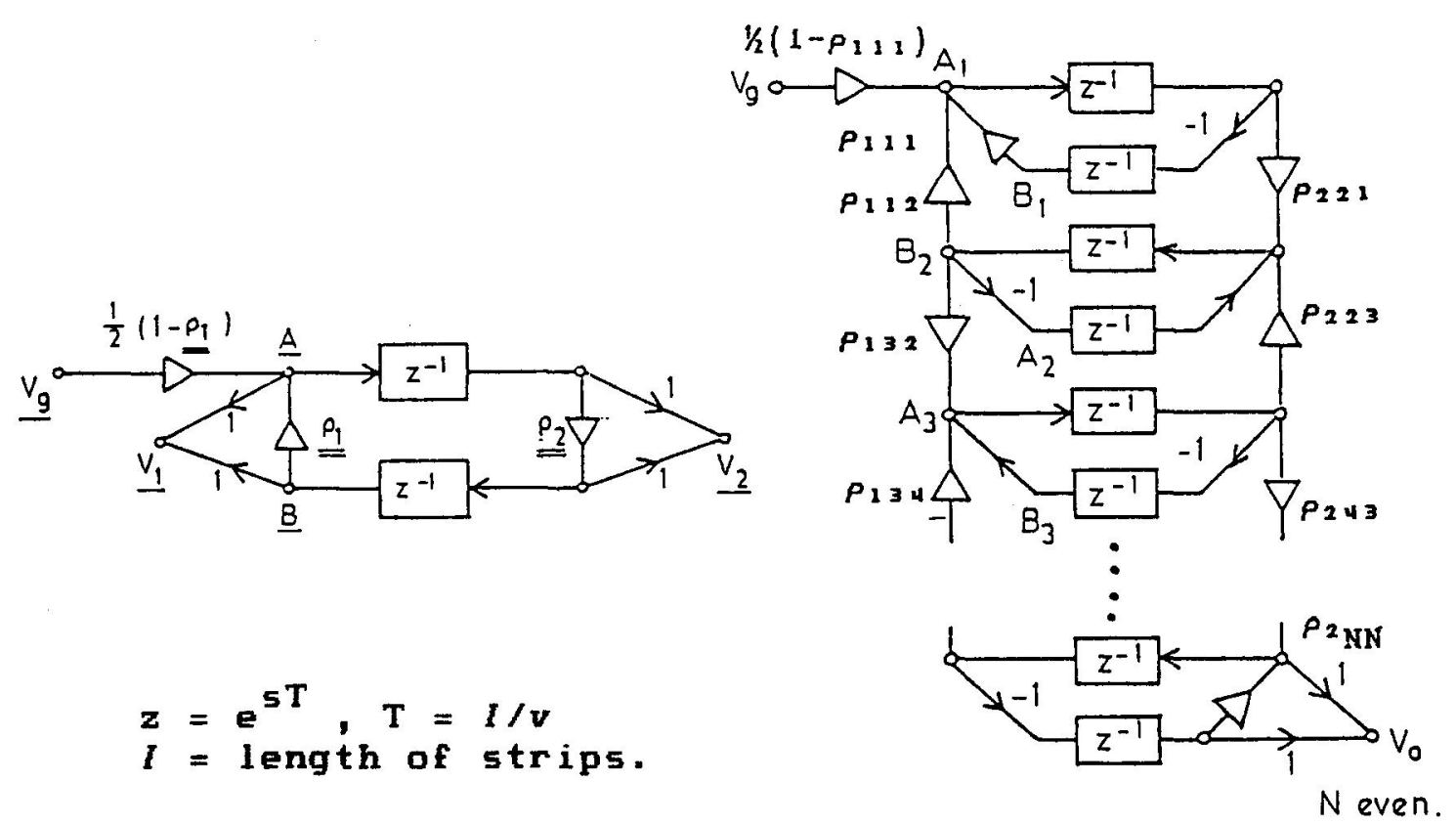

Fig. 1 Flow graphs for an even order SCTL interdigital filter or a DIF. a) The matrix (state space) flow graph.

b) The "unfolded" flow graph. 
The terminating impedances may be chosen to make the filter into a SCTL- or a OCTL-interdigital filter or a combline filter etc.

The flow graph representation of the matrix equation (1) for a scTL interdigital filter is shown in fig.1, where also the "unfolded" version of the flow graph is shown. This flow graph is simple, because the reflexion coefficient matrices $\underline{e}_{1}$ and $\underline{e}_{2}$ (2), (3) each only have $2 \mathrm{~N}-1$ elements different from 0 , and $N-1$ of these are equal to +1 or -1 .

In the case of a DIF, the flow graph may be simplified drastically, so that the corresponding digital filter only has $N+1$ multipliers. The digital filter is very 5 imple and has exellent properties, and it may easily be changed into e.g. a lowpass filter.

\section{DESIGI FORFULAS FOR A SCTL-IKTERDIGITAL FILTER:}

The flow graph in fig. 1b represents a $N+2$ strip Nth order filter. The two outer strips transforms the impedance level. The condition under which this is true is that the elements $P_{1,11}$ and $P_{2, N N}(N$ even) in the refexion coefficient matrices are 0 . This corresponds to utilizing one of the well known Ruroda identities. With $P_{1,11}=0$ and $P_{2, N N}=0$ (for $N$ even), the flowgraph may be reduced to the flowgraph shown in fig.2.

The flow graph now represents a $N$ strip filter and thus a Nth order bandpass filter (2.Nth order in $z$ ). The remaining problem is to find expressions for the elements in the capacitance matrix for the $N+2$ strips. Using the design formulas for a Nth order DIF presented in the full paper [1] and utilising some signal flow graph theory together with the theory presented in [2] to [5], it is found that the reflexion coefficient elements can be expressed as shown in the equations (5) to (8). Here the constants $g_{1}, g_{2}, g_{3}$ etc. are the normalized all pole lowpass filter components. Observe that the element $C_{11}$ in the capacitance matrix is deter mined by the equation (5) $P_{1,11}=0$.

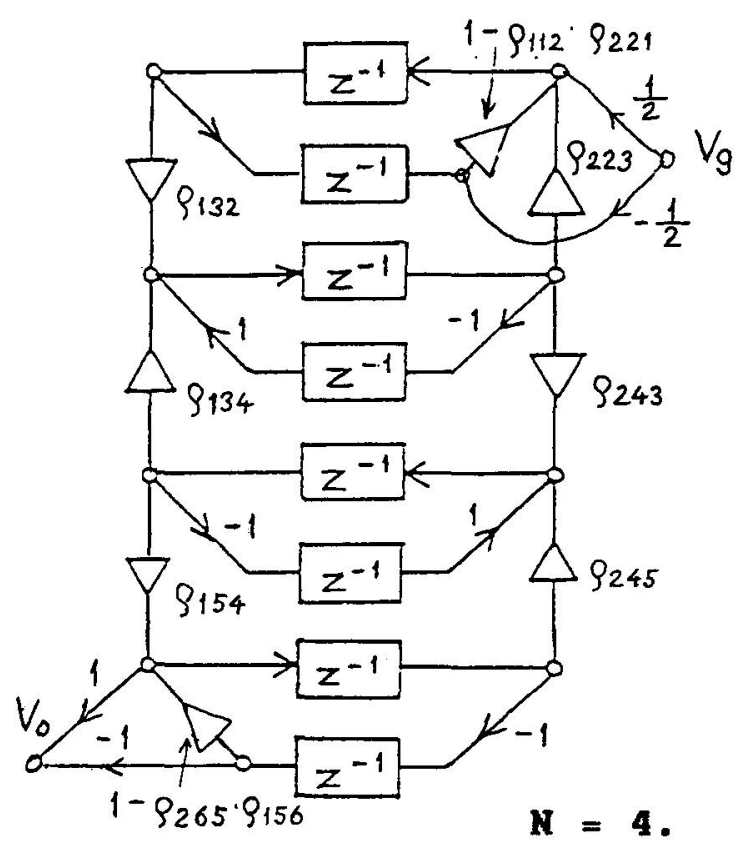

Fig.2 Simplified flow graph for $N+2$ strip SCTL interd. filter.

$$
\begin{aligned}
& P_{1,11}=\left(\mathrm{Z}_{0} \cdot v \cdot \mathrm{C}_{11}-1\right) /\left(\mathrm{Z}_{0} \cdot v \cdot \mathrm{C}_{11}+1\right)=0 \\
& P_{1,12} \cdot P_{2,21}=2 \cdot \pi \cdot \mathrm{B}_{\mathrm{rel}} /\left(4 \cdot g_{1}+\pi \cdot \mathrm{B}_{\mathrm{rel}}\right)
\end{aligned}
$$




$$
\begin{aligned}
& P_{1,32} \cdot P_{2,23}=\left(\pi \cdot B_{r e 1}\right)^{2} /\left(\left(4 \cdot g_{1}+\pi \cdot B_{r e 1}\right) \cdot g_{2}\right) \\
& P_{1,34} \cdot P_{2,43}=\left(\pi \cdot B_{r e 1}\right)^{2} /\left(4 \cdot g_{2} \cdot g_{3}\right) \\
& \text { etc. } \\
& B_{r e 1}=2 \cdot \pi \cdot B / \omega_{0} \cdot B=\text { the bandwidth. }
\end{aligned}
$$

Observe that except for $P_{1,11}$ and $P_{2, N N}$ it is the product of reflexion coefficient elements that determine the filter response.

The expressions (2) and (3) give the elements of the reflexion coefficient matrices in terms of the capacitance matrix elements. The resulting very simple design formulas (9) to (15) for SCTL interdigital filters are presented below.

$$
\begin{aligned}
& Z_{0} \cdot v \cdot C_{11}=1, v=c / \sqrt{\varepsilon_{r}}, \quad Z_{0}=50 \Omega \text { normally } \\
& Z_{0} \cdot v \cdot C_{12}=-\sqrt{\frac{k_{1}}{g_{1} \cdot T+1}} \\
& \mathrm{Z}_{0} \cdot v \cdot \mathrm{C}_{22}=\mathrm{k}_{1} \\
& \mathrm{Z}_{0} \cdot v \cdot \mathrm{C}_{23}=-(1 / \mathrm{T}) \cdot \sqrt{\frac{\mathrm{K}_{1} \cdot \mathrm{K}_{2}}{\left(\mathrm{~g}_{1}+1 / \mathrm{T}\right) \cdot \mathrm{g}_{2}}} \\
& \mathrm{Z}_{0} \cdot \mathrm{v} \cdot \mathrm{C}_{33}=\mathrm{k}_{2} \\
& Z_{0} \cdot v \cdot C_{34}=-(1 / T) \cdot \sqrt{\frac{k_{2} \cdot k_{3}}{g_{2} \cdot g_{3}}} \\
& \mathrm{Z}_{0} \cdot \mathrm{v} \cdot \mathrm{C}_{44}=\mathrm{k}_{3} \\
& \text { etc. } \\
& T=\left(\pi \cdot B_{\mathrm{rel}} / 4\right)^{-1}
\end{aligned}
$$

The constants $k_{1}, k_{2} \ldots$ may in theory be chosen arbitrarily, but practical considerations limit the choice. Compare these formulas with the corresponding formulas in [6].

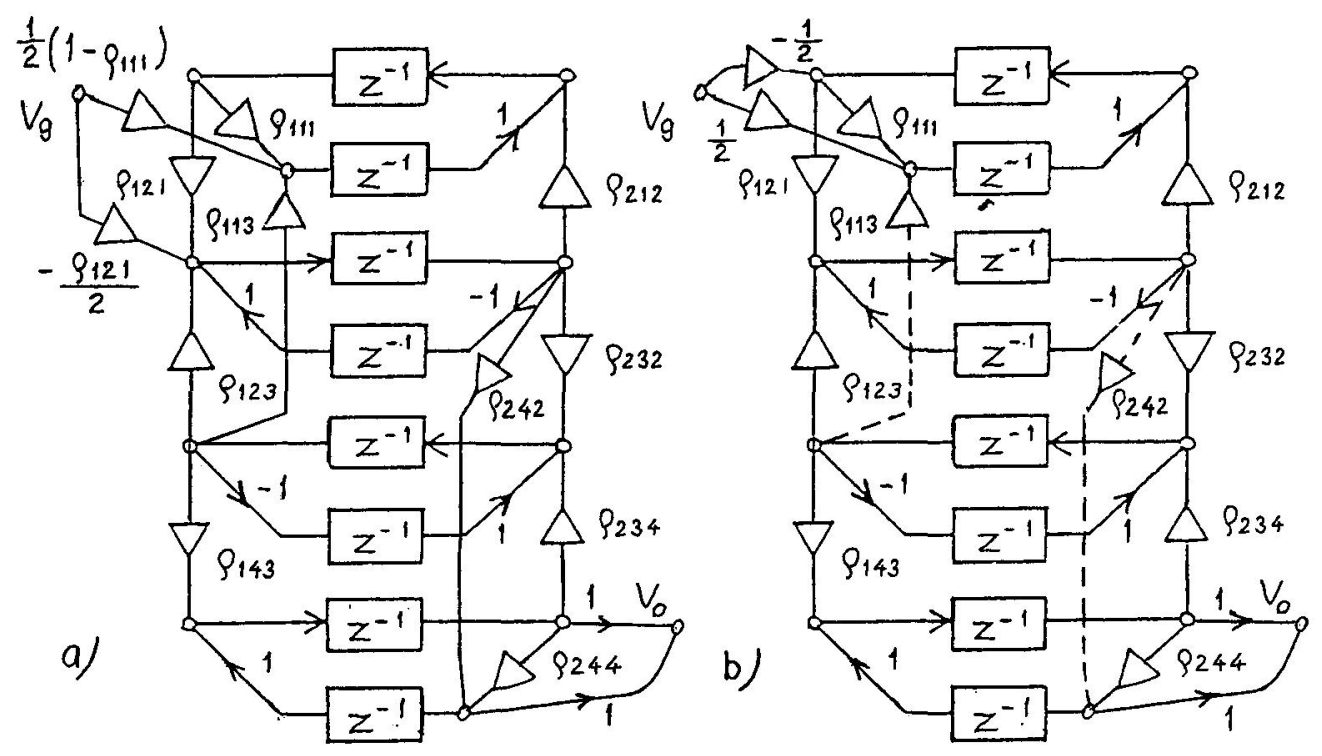

Fig.3. a) The OCTL interdigital filter flow graph. b) The reduced flow graph. $\quad k=4$. 
The unfolded flow graph for a OCTL filter is shown in $\mathrm{ig.3a.}$ It is somewhat more complicated than the 5CTL flow graph. However, by again utilizing some signal flow graph theory, the flow graph may be reduced to the flow graph presented in fig.3b. Except for the elements $P_{1,13}$ and $P_{2,42},(N=4)$, the flowgraph is almost identical to the flow graph for the SCTL filter. These two elements are very small but do have some influence on the transfer function. The design equations for an Nth order DIF [1] may be used for the Nth order OCTL filter, with a little modification. The resulting design equations are presented below (16) to $(21)$.

$$
\begin{aligned}
& \text { Define } g_{1}=g_{1}-1 /\left(T^{2} \cdot g_{2}\right) \text { and } g_{2}^{\prime}=g_{2} \cdot g_{1} / g_{1} \cdot \\
& Z_{0} \cdot v \cdot C_{11}=1 /\left(T \cdot g_{1},\right) \\
& Z_{0} \cdot v \cdot C_{12}=-\left(1 /\left(T \cdot g_{1},\right)\right) \cdot \sqrt{\frac{k_{1}}{T \cdot g_{2}}} \\
& Z_{0} \cdot v \cdot C_{22}=k_{1} \\
& Z_{0} \cdot v \cdot C_{23}=-(1 / T) \cdot \sqrt{\frac{k_{1} \cdot k_{2}}{g_{2} \cdot g_{3}}} \\
& Z_{0} \cdot v \cdot C_{33}=k_{2} \\
& Z_{0} \cdot v \cdot C_{34}=-(1 / T) \cdot \sqrt{\frac{K_{2} \cdot k_{3}}{g_{3} \cdot g_{4}}} \\
& Z_{0} \cdot v \cdot C_{44}=k_{3} \\
& \text { etc. Here presented for } N, 4 .
\end{aligned}
$$

\section{Q DESIGI EXAMPLE.}

A 7 th order (14th. order in z) 0.5 dB ripple Chebyshev bandpass DIF or a 9 strip SCTL interdigital stripline filter with $50 \%$ relative bandwidth was designed using the design formulas presented above. A 50\% bandwidth is rather large. A SCTL interdigital transmission line filter will in fact be impractical with this bandwidth.

Fig 4 shows the output from a digital filter analysis program developed by the author. This is also the theoretical response for an ideal stripline interdigital filter. The theoretical response for a microstrip sCTL interdigital filter ( $\varepsilon_{r}=2.37$ ) is also shown. The actual design method for the microstrip filter is a combination of the design method presented in [2] to [5] and the method used for a DIF.

\section{COMCLUSTOR.}

The introduction of a state variable description for interdigital transmission line filters led to the development of a simple state Space Wave Digital Filter with exellent properties, a filter which hitherto has been deemed impractical. A simple design procedure for this digital filter was developed, which again led to simple design formulas for interdigital transmission 1 ine filters. 


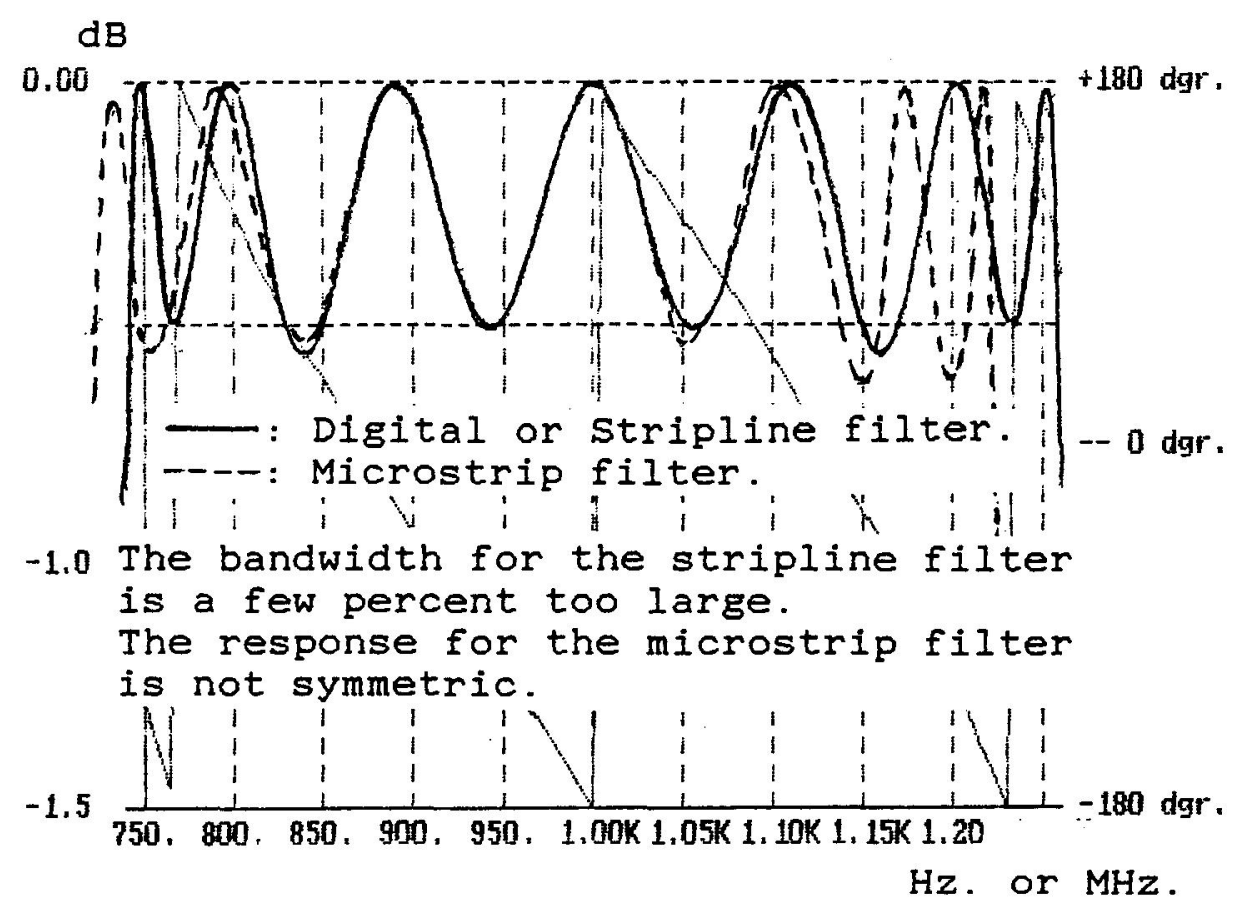

Fig.4. The filter response for a digital filter, a stripline filter and a microstrip SCTL interdigital filter.

\section{BEFEREMCES:}

1: A.B.Dalby, "A Microwave Digital Filter or a Digital Microwave Filter." Onzieme Collaque Gretzi, Nice du ler au 5 juin 1987. Book of proceedings pp 25-28.

2: A.B.Dalby, "Analysis and Synthesis of Microstrip circuits with more than two Coupled Strips." 7th. European Microwave Conference, book of proceedings pp 441-445. September 1977.

3: A.B.Dalby, "Interdigital Microstrip Circuit Parameters using Empiricai Formulas and 5 implif ied Model." IEEE MTT-S International Microwave Symposium Digest pp 223-226. June 1978.

4: A.B.Dalby, "Interdigital Microstrip Circuit Parameters using Empirical Formulas and $S$ implified Model." IEEE Transactions on MTT, vol. MTT-27. No 8. pp 744-752. August 1979.

5: A.B.Dalby, "On Coupled Thick Microstrips". 16th European Microwave Conference in Dublin, September 8-11, 1986. Conference proceedings page 535-540. The full paper with computer program may be obtained from the author. Some errors are corrected.

6: Fatthei, Young and Jones, "Microwave filters, Impedance matching networks, and coupling structures. McGRAw-HILL 1964.

7: Alfred Fettweis, "Digital Circuits and Systems". IEEE Transactions on CAS, vol CAS-31, No. 1, pp 31-48. January 1984. 